\title{
Article \\ Greenspace Inversely Associated with the Risk of Alzheimer's Disease in the Mid-Atlantic United States
}

\author{
Jianyong $\mathrm{Wu}^{1, *(\mathbb{D}) \text { and Laura Jackson }}{ }^{2}$ \\ 1 Oak Ridge Institute for Science and Education, hosted by US EPA, Office of Research and Development, \\ Research Triangle Park, Durham, NC 27711, USA \\ 2 US EPA, Office of Research and Development, Center for Public Health and Environmental Assessment, \\ Research Triangle Park, Durham, NC 27711, USA; Jackson.laura@epa.gov \\ * Correspondence: Jianyong.wu@alumni.unc.edu
}

check for updates

Citation: Wu, J.; Jackson, L. Greenspace Inversely Associated with the Risk of Alzheimer's Disease in the Mid-Atlantic United States. Earth 2021, 2, 140-150. https://doi.org/ 10.3390/earth2010009

Received: 25 January 2021

Accepted: 26 February 2021

Published: 28 February 2021

Publisher's Note: MDPI stays neutral with regard to jurisdictional claims in published maps and institutional affiliations.

Copyright: (c) 2021 by the authors. Licensee MDPI, Basel, Switzerland. This article is an open access article distributed under the terms and conditions of the Creative Commons Attribution (CC BY) license (https:/ / creativecommons.org/licenses/by/ $4.0 /)$.

\begin{abstract}
Alzheimer's disease (AD) is a chronic neurodegenerative disease and the most common form of dementia in older adults. Treatment of AD symptoms is very challenging and expensive. Appropriate diet as well as mental and physical activity may delay or reduce the occurrence of AD. It is unknown whether environmental factors offer potentially protective effects against the development of AD. We explored the possible beneficial effects of greenspace (trees and herbaceous cover) on the rate of AD in the mid-Atlantic US. Data for initial AD medical claims during 2011-2013 were obtained from Medicare records for 2999 ZIP codes. The percentages of land cover classes in each ZIP code were calculated based on high-resolution land cover imagery. Associations between $\mathrm{AD}$ and greenspace, blue space (water), and other variables were examined using zero-inflated Poisson models. The rate of $\mathrm{AD}$ was negatively associated with greenspace (for a greenspace increase of $10 \%$, risk ratio $(\mathrm{RR})=0.91,95 \%$ confidence interval $(\mathrm{CI}): 0.89-0.94)$, and blue space (for a water area increase of $10 \%, \mathrm{RR}=0.85,95 \% \mathrm{CI}$ : $0.81-0.89)$. The inverse relationships between greenspace and the risk of $\mathrm{AD}$ held across season, gender, and race. The rate of $\mathrm{AD}$ was positively associated with the concentration of fine particulate matter (PM2.5) $(\mathrm{RR}=1.03,95 \% \mathrm{CI}: 1.02-1.05$ for an increase in PM2.5 of $1 \mu \mathrm{g} / \mathrm{m}^{3}$ ). Our results suggest that greenspace may have protective effects for $\mathrm{AD}$, although potential mechanisms are unclear and require further investigation.
\end{abstract}

Keywords: greenspace; blue space; Alzheimer's disease; PM2.5; environmental health

\section{Introduction}

Alzheimer's disease (AD) is a progressive neurodegenerative disease that gradually impairs memory and thinking skills, leading to the loss of independence and the inability to perform the basic activities of daily life [1]. The overproduction of the amyloid- $\beta$ (A $\beta$ ) peptides and hyperphosphorylation of the Tau protein and its subsequent deposition are hypothesized as two major mechanisms to develop AD [2,3]. While its mechanism is unknown, it is the most common cause of dementia in older adults and is ranked as the sixth leading cause of mortality in the US. More than 5 million people may currently have AD in the US; this number is expected to rise rapidly in the next decades $[4,5]$.

$\mathrm{AD}$ is irreversible, and while certain drugs may alleviate some symptoms of AD, none can cure it or stop its progression [6]. Total costs for health care and long-term care are estimated at hundreds of billions of dollars, posing a considerable financial burden on families and making it the most expensive disease in the US [4].

AD may have both genetic and non-genetic factors that play roles in its development [1,7]. Age is the primary risk factor for AD [8] with nearly 95\% of AD patients aged 65 and older [1]. Family history is the second largest risk for AD, and genetics may be responsible for $80 \%$ of cases [9]. Polymorphisms in ApoE, SORL1, and GSK3 genes are thought to be the major genetic risk factors [10-12]. For non-genetic factors, cerebrovascular disease, high blood pressure, Type 2 diabetes, heavy body weight, high plasma 
lipid levels, metabolic syndrome, smoking, and traumatic brain injury have been found to be positively associated with AD. Environmental pollutants as a risk factor for AD have also been gradually recognized [10]. Studies have found that metals (mercury, arsenic), insecticides/pesticides, nanoparticles, and air pollutants might induce AD or AD-like progression in animal and human subjects $[10,13,14]$. Several epidemiological studies have also found that long-term exposure to fine particulate matter (PM2.5), one of the major traffic-related air pollutants, was positively associated with AD incidence [15-17].

Some factors may offer protection from AD. For example, diet (e.g., Mediterranean food), physical exercise, and intellectual activity may reduce AD risk [4,5]. Greenspace, such as trees, gardens, and parks, has been found to provide many human health benefits because of the filtration of air pollutants, promotion of physical activity and social contact, and reduction of stress and depression $[18,19]$. Recent studies have shown that exposure to greenspace may be beneficial to mental health and brain health [20,21]. Greenspace may be an environmental protective factor for human health, including for AD. However, the relationship between greenspace and $\mathrm{AD}$ is unknown. Water views in the landscape have frequently been expressed as a human preference (reflected in real-estate values and vacation destinations) and a restorative element $[22,23]$. While research on mental health or cognitive benefits of blue space is scarce [24], time spent at the beach has been linked to healthy behavioral development in Barcelona schoolchildren [25]. Therefore, this study examined the association of green and blue spaces with the rate of AD in the mid-Atlantic US. It also sought to replicate previously documented associations between AD rate and PM2.5, and to control for PM2.5 in models since PM2.5 has been identified as a possible risk factor for AD. Furthermore, by assessing natural infrastructure and air pollution in combination, this study may offer insights into possible protective effects of vegetation on AD through particulate entrapment [26].

\section{Materials and Methods}

\subsection{Study Area}

Our study area encompassed 2999 postal ZIP codes in the mid-Atlantic United States (all or parts of New York, Pennsylvania, Delaware, Maryland, West Virginia, Virginia, and Washington, DC, Figure 1). It was selected because the effects of PM2.5 on human neurological diseases have been observed here [16]. In addition, a high-resolution $(1 \mathrm{~m})$ land cover dataset is available for this area. According to the US Census Bureau's American Community Survey for 2009-2013, the area had a population of 26 million.

\subsection{Alzheimer's Disease Data}

The AD data were obtained from Medicare enrollees aged $\geq 65$ whose medical records are held by the Center for Medicaid and Medicare (CMS). The whole dataset contains the records from 1999 to 2013. In the CMS dataset, each enrollee has a unique identification number and codes to indicate the types of diagnoses according to the International Classification of Disease-Ninth Revision (ICD 9). For enrollees with records of AD (ICD 9 code 331.0) during the study period, we extracted the earliest record for analysis. Specifically, we selected the first record of a patient who was diagnosed with the AD from the dataset and then selected the data for 2011-2013 to most closely match the high-resolution land cover data. Information about the date (year, month, and day) of health care, residential location (ZIP code, county and state), race, and gender were also available. As the specific address for each patient was withheld, we analyzed the data at the ZIP code level. The data were also aggregated by month to correspond to the PM2.5 data.

\subsection{Land Cover Data}

A 2013-2014 classified land cover dataset for the study area was obtained from the Chesapeake Bay Innovation Center [27]. This one-meter resolution dataset is derived from photography collected by the USDA National Aerial Imagery Program and covers approximately $259,000 \mathrm{~km}^{2}$ in and around the Chesapeake Bay watershed. The land cover 
was originally classified into 6 major categories: water, trees (including shrubs), herbaceous, barren, impervious, and roads. We combined the tree and herbaceous classes into one greenspace class and calculated the percentage of each resulting type of land cover by ZIP code using 2010 ZIP code from the US Census Bureau [28].

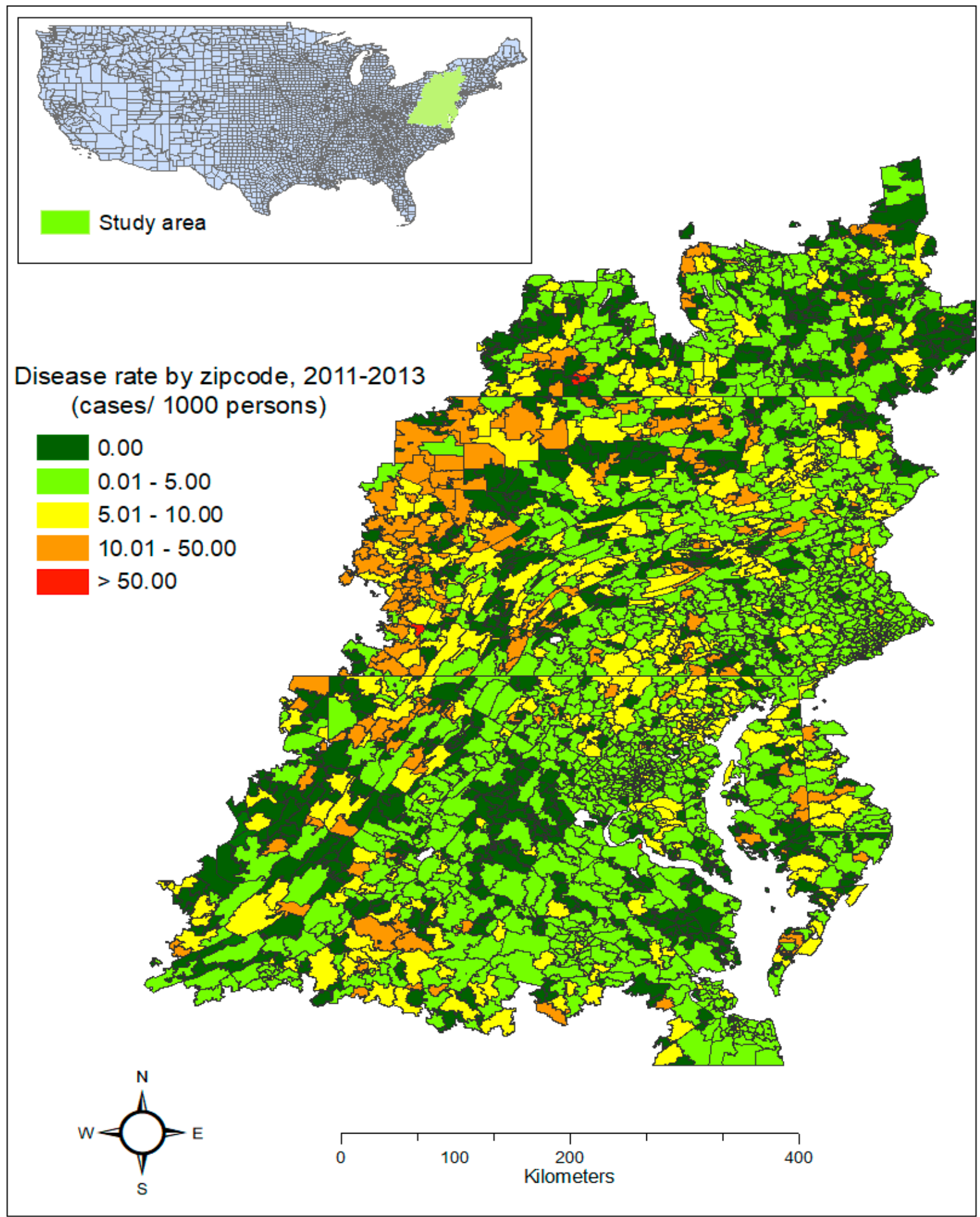

Figure 1. Rate of initial Alzheimer's disease claims in the study area during 2011-2013.

We also obtained data for major roadways in the study area from NavTEQ ${ }^{\mathrm{TM}}$ (Chicago, IL, USA, the leading provider of maps, traffic and location data in North America). Using ArcGIS 10.3 (ESRI, CA, USA), we calculated density of major roads (interstate, state high- 
ways, and major arterials) by ZIP code using the total length of major roads in a ZIP code divided by the total area of that ZIP code.

\subsection{PM2.5 Data}

We obtained PM2.5 data for the study area from the U.S EPA [29]. These are estimates at the census tract level, which were downscaled from regional models and fused with data from field monitors. We assigned these PM2.5 values to ZIP codes using a nearest neighborhood method. Specifically, we calculated the distances between census tract and ZIP code centroids. A PM2.5 value assigned to a ZIP code was the same as the value of the nearest census tract.

\subsection{Demographic and Socioeconomic Status Data}

We obtained demographic and socioeconomic status data for each ZIP code from the US Census Bureau's five-year American Community Survey for 2009-2013. We restricted the population data to age 65 and above because the Medicare data represents primarily this age group. Additionally, AD emerges primarily from within this population [1].

We calculated the percentage of this population in each ZIP code by gender and predominant race (white and black) for stratified analyses. We used the median annual household income to indicate socioeconomic status (SES) by ZIP code. Population density was calculated using the total population in a ZIP code divided by its area.

\subsection{Statistical Analysis}

We used the zero-inflated Poisson model [30] to examine the association between AD and exploratory variables since the response variable, the number of earliest-identified AD records in each ZIP code during the study period, is count data with excess zeros. The exploratory variables included monthly average PM2.5 concentration, percent greenspace, percent water area, median annual household income, ZIP code area, population density, and road density. The natural-log transformed population (age $\geq 65$ ) data was used as the off-set term in the model. We checked for outliers in the response variable and removed extreme large values based on the histogram of the data (nearly 1\% of observations) from the dataset. Then, we examined multicollinearity among exploratory variables using correlation analysis and variance inflation factors (VIF) [31]. If two or more variables were highly correlated (i.e., $r>0.6$ ), only one variable was included in the model. We also selected the exploratory variables based on the value of the Akaike information criterion (AIC). A smaller AIC suggests a model with a better fit. The statistical analysis was conducted with SAS 9.4 (SAS Institute, Inc, Cary, NC, USA).

We used risk ratios (RRs) to assess the strength of associations between AD and the exploratory variables. If an RR was above 1.00, a positive association was assumed, while if it was below 1.00, a negative or inverse association was assumed. We chose the significance level at 0.05 . Greenspace and water were modeled in $10 \%$ increments to reflect more meaningful land cover change, as the effects of $1 \%$ changes in greenspace and water are trivial [21]. Thus, the RRs for greenspace and water indicate the changes in the risk of $\mathrm{AD}$ when these land cover variables increase by $10 \%$. To evaluate seasonal effects on the associations, we stratified the monthly data into spring (March, April, and May), summer (June, July, and August), autumn (September, October, and November) and winter (December, January, and February), and then ran the model for each season. We also stratified the model by gender and race.

\section{Results}

\subsection{Description of AD Data and Explanatory Variables}

Monthly AD by ZIP code ranged from 0 to 5, with a mean value of 0.067 and a standard deviation of 0.29 (Table 1). Monthly average PM2.5 concentration by ZIP code was $9.073 \pm 2.252 \mu \mathrm{g} / \mathrm{m}^{3}$ (Table 1 ). Greenspace was the major land cover type, accounting for $85.01 \pm 17.51 \%$. Water area accounted for $3.74 \pm 9.25 \%$ (Table 1 ). The median 
annual household income was $\$ 29,315 \pm 11,805$ and the mean population density was $5.3 \pm 18.96$ persons $/ \mathrm{km}^{2}$ (Table 1$)$. The percentages of males and females were approximately equal (Table 1). In the study area, the major race was white, accounting for $85.63 \%$ of the population. The black population accounted for $9.34 \%$.

Table 1. Descriptive statistics of key variables by ZIP code.

\begin{tabular}{|c|c|c|c|c|c|}
\hline Variables & No. Observations & Mean & $\begin{array}{l}\text { Standard } \\
\text { Deviation }\end{array}$ & Minimum & Maximum \\
\hline \multicolumn{6}{|l|}{ Medicare claims data } \\
\hline Initial AD claims /month & 106,763 & 0.067 & 0.290 & 0 & 5 \\
\hline Monthly claim rate & 106,763 & $2.6 \times 10^{-6}$ & $1.3 \times 10^{-6}$ & 0 & $3.98 \times 10^{3}$ \\
\hline \multicolumn{6}{|l|}{ Environmental data } \\
\hline PM2.5 $\left(\mu \mathrm{g} / \mathrm{m}^{3}\right)$ & 106,763 & 9.073 & 2.252 & 4.485 & 0.053 \\
\hline Greenspace (\%) & 106,763 & 85.013 & 17.508 & 7.08 & 99.77 \\
\hline Water $(\%)$ & 106,763 & 3.735 & 9.248 & 0 & 85.73 \\
\hline \multicolumn{6}{|l|}{ Covariates } \\
\hline Median income $(\$)$ & 105,073 & 29315 & 11805 & 2542 & 135865 \\
\hline Male population (\%) & 106,763 & 50.028 & 7.753 & 0 & 100 \\
\hline Female population $(\%)$ & 106,763 & 49.972 & 7.753 & 0 & 100 \\
\hline White population $(\%)$ & 106,763 & 85.623 & 19.828 & 0 & 100 \\
\hline Black population $(\%)$ & 106,763 & 9.338 & 16.976 & 0 & 100 \\
\hline ZIP code area $\left(\mathrm{km}^{2}\right)$ & 106,763 & 80.564 & 100.716 & 0.007 & 872.515 \\
\hline $\begin{array}{l}\text { Population density } \\
\left(1000 / \mathrm{km}^{2}\right)\end{array}$ & 106,763 & 5.300 & 18.961 & 0.001 & 712.326 \\
\hline Road density $\left(\mathrm{km} / \mathrm{km}^{2}\right)$ & 109,405 & 0.789 & 1.711 & 0 & 58.555 \\
\hline
\end{tabular}

Medicare claim: An application for Medicare coverage of a medical visit or procedure. Monthly rate: monthly initial AD records/population aged 65 and above.

The results of Pearson correlation analysis showed that both monthly AD and AD rate were positively correlated with PM2.5, median income, population density, percentages of female and black populations, road density, and ZIP code area $(r>0.0, p<0.01)$, but they were negatively correlated with the percentage of greenspace and water area, and the percentages of male and white populations (Table 2).

Table 2. Pearson correlation between monthly initial records and rates of Alzheimer's disease and exploratory variables.

\begin{tabular}{ccccc}
\hline Variables (Unit) & \multicolumn{2}{c}{ Monthly Initial Records } & \multicolumn{1}{c}{ Monthly Rate } \\
\cline { 2 - 5 } & $\boldsymbol{r}$ & $\boldsymbol{p}$ & $\boldsymbol{r}$ & $<$ \\
\hline PM2.5 $\left(\mu \mathrm{g} / \mathrm{m}^{3}\right)$ & 0.069 & $<0.001$ & 0.050 & $<0.001$ \\
Greenspace $(\%)$ & -0.099 & $<0.001$ & -0.057 & $<0.001$ \\
Water $(\%)$ & -0.002 & $<0.001$ & -0.021 & $<0.001$ \\
Median income (\$) & 0.030 & $<0.001$ & 0.027 & $<0.001$ \\
Population density & 0.059 & $<0.001$ & 0.060 & $<0.001$ \\
Male population $(\%)$ & -0.047 & $<0.001$ & -0.026 & $<0.001$ \\
Female population (\%) & 0.0465 & $<0.001$ & -0.076 & $<0.001$ \\
White population $(\%)$ & -0.125 & $<0.001$ & 0.061 & $<0.001$ \\
Black population (\%) & 0.104 & $<0.001$ & 0.025 & $<0.001$ \\
Road density $\left(\mathrm{km} / \mathrm{km}^{2}\right)$ & 0.031 & $<0.001$ & 0.062 & $<0.001$ \\
ZIP code area $\left(\mathrm{km}^{2}\right)$ & 0.062 & & \\
\hline
\end{tabular}

\subsection{Modeled Associations}

The results from the final zero-inflated Poisson model are presented in Table 3. Five explanatory variables were included in the final model, which are PM2.5 concentration, the percentage of greenspace, the percentage of water, median income, and population density. The results showed that AD rate was positively associated with PM2.5 (for a $1 \mu \mathrm{g} / \mathrm{m}^{3}$ increase in PM2.5 concentration, $\mathrm{RR}=1.03,95 \%$ confidence interval $(\mathrm{CI})=1.02-1.05)$ (Table 3$)$. In contrast, $\mathrm{AD}$ rate had a negative association with greenspace ( $\mathrm{RR}=0.91$, 
$95 \% \mathrm{CI}=0.89-0.94)$ and with water area $(\mathrm{RR}=0.85,95 \% \mathrm{CI}=0.81-0.89)$ (Table 3). Both median annual household income and population density had significant negative associations with $\mathrm{AD}$ rate ( $\mathrm{RR}=0.90$ and 0.91 , respectively) (Table 3).

Table 3. Association between Alzheimer's disease and exploratory variables.

\begin{tabular}{cccc}
\hline Exploratory Variables (Unit) & RR & $\mathbf{9 5 \%}$ CI & $p$ \\
\hline PM2.5 $\left(\mu \mathrm{g} / \mathrm{m}^{3}\right)$ & 1.03 & $1.02-1.05$ & $<0.001$ \\
Greenspace $(10 \%)$ & 0.91 & $0.89-0.94$ & $<0.001$ \\
Water $(10 \%)$ & 0.85 & $0.81-0.89$ & $<0.001$ \\
Median income $(\$ 10,000)$ & 0.90 & $0.88-0.92$ & $<0.001$ \\
Population density $\left(1000 / \mathrm{km}^{2}\right)$ & 0.91 & $0.88-0.93$ & $<0.001$ \\
\hline
\end{tabular}

\subsection{Seasonal Effects on the Associations}

$\mathrm{AD}$ was positively associated with PM2.5 across seasons. The association was slightly stronger in the summer $(R R=1.08,95 \% C I=1.05-1.10)$ and weaker in the winter $(R R=1.04$, $95 \%$ CI $=1.02-1.06$ ) (Figure 2). Negative associations were observed for greenspace, water, median income, and population density for all four seasons (Figure 2). The association with greenspace was slightly stronger in spring and autumn but slightly weaker in winter. Similarly, the association with water was slightly stronger in autumn but slightly weaker in winter. Overall, the associations in winter were slightly weaker than those in other seasons, but the differences were not statistically significant (Figure 2).

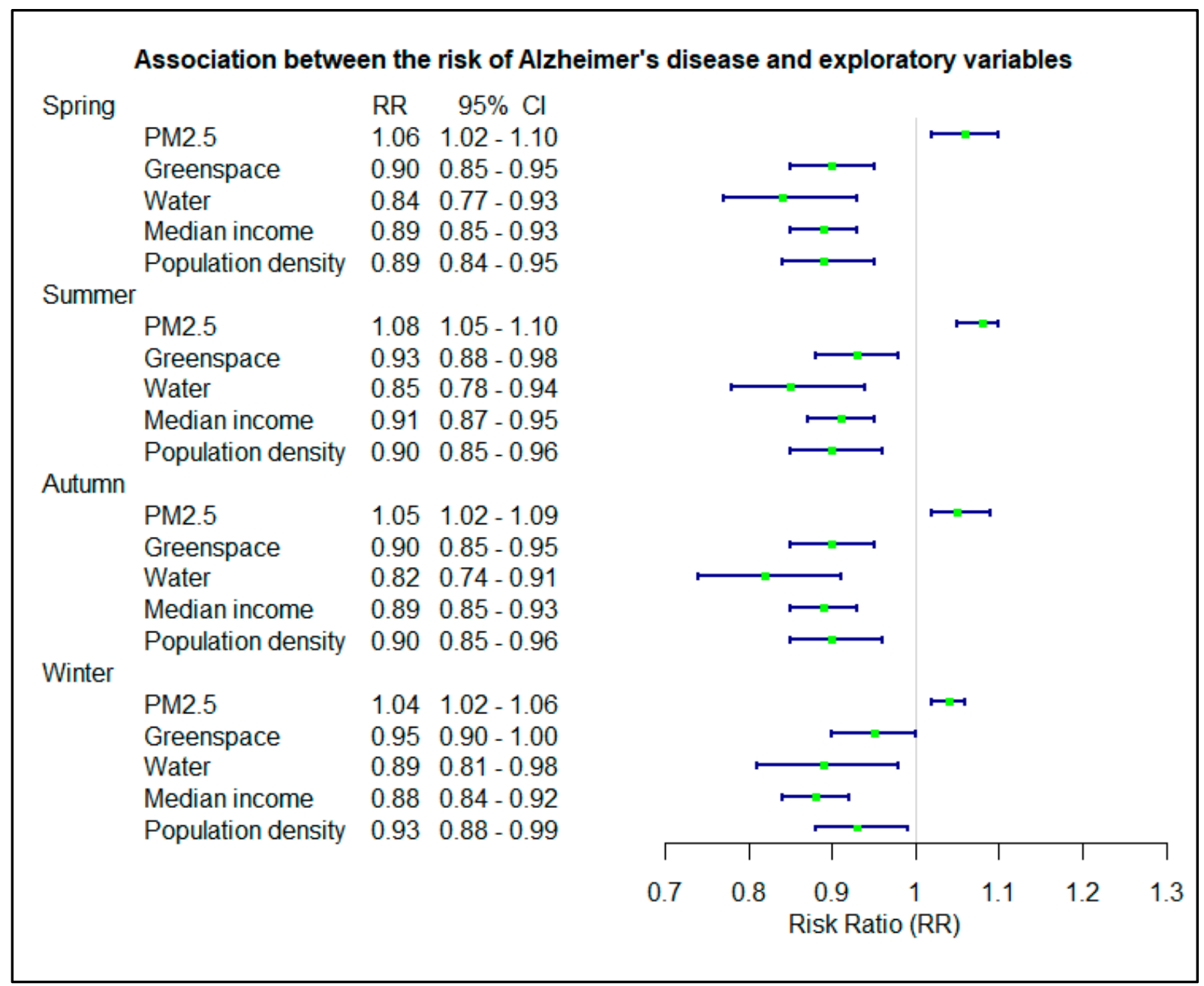

Figure 2. Association between the risk of Alzheimer's disease and exploratory variables in different seasons. 


\subsection{Association Stratified by Gender and Race}

The gender and race stratified models showed that associations between $\mathrm{AD}$ rate and exploratory variables were similar across strata (Figure 3 ). However, the association with PM2.5 was extremely significant $(p<0.01)$ in white subjects but only slightly significant $(p=0.05)$ in black subjects. The AD rate had a significant negative association with median income for white patients but not for black patients (Figure 3).

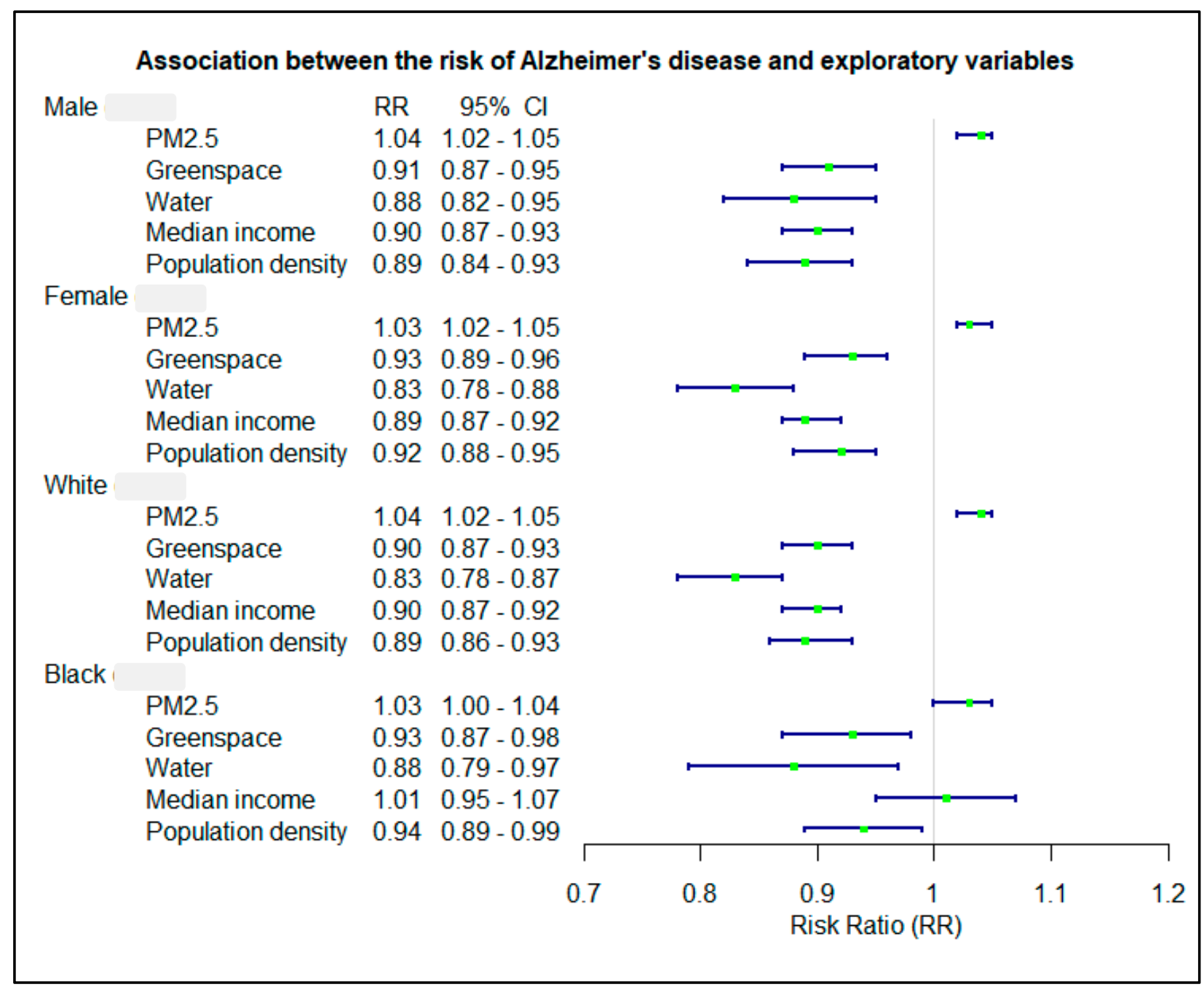

Figure 3. Association between the risk of Alzheimer's disease and exploratory variables in different gender and race.

\section{Discussion}

We conducted a large-scale ecological analysis to explore the connection between AD rate and exposure to greenspace and blue space in the mid-Atlantic US. By analyzing AD from Medicare records and land cover measured by high-resolution imagery, we found a significant inverse relationship between $\mathrm{AD}$ rate and the percentages of greenspace and water area. The results were consistent when we stratified the model by season, gender, and race and controlled for confounding variables including income and population density. Our study is the first to investigate the possible protective effects of greenspace and blue space on $\mathrm{AD}$ rate. Findings from this study suggest that exposure to greenspace and blue space may reduce the risk of developing or delay the onset of $\mathrm{AD}$, providing a new insight to mitigate the high incidence of the disease.

The negative association between greenspace and $\mathrm{AD}$ rate in the study area may be due to air pollutant filtration by trees and other vegetation $[32,33]$. It was estimated 
that nearly 17,400 million $\mathrm{kg}$ of air pollutants were removed by forests and trees in the conterminous United States in 2010 [34]. Herbaceous cover has also been found to take up air pollutants, including PM2.5 [35]. Previous studies have shown that air pollutants are one of the major environmental risk factors for AD, especially traffic-related air pollutants such as PM2.5 [15-17]. Our previous study also suggested that greenspace may have a benefit to brain health through buffering traffic-related air pollution [21]. Generally, air pollution is more serious in urban than in rural areas. However, rural areas can have elevated vehicular air pollutant levels due to diesel highway trucks and farm vehicles.

Greenspace may also reduce the risk of AD by promoting physical activity such as jogging, walking, and biking. Physical exercise may support the maintenance of brain volume, and mitigate obesity, hypertension, stroke, and other AD risk factors [36]. Physical activity has been negatively associated with dementia and is generally regarded as protective [37]. Greenspace (e.g., greenway trails, parks, and gardens) provides attractive and safe places for physical activities, and as such, it may confer substantial health benefits [38-40]. Furthermore, greenspace may play a protective role in the risk of AD through depression reduction. The connection between depression and AD has long been recognized [41,42]. For example, one study has shown that depressed patients were more cognitively impaired and more disabled in daily activities [42]. A systematic review and meta-analysis concluded that late-life depression has positive associations with the risk for Alzheimer's disease and all-cause dementia [43]. Exposure to tree canopy, which is best associated with perceived greenspace [44], may reduce the risk of dementia such as AD through stress reduction. A large study in Australia showed exposure to tree canopy was associated with a lower risk of dementia [45]. Meanwhile, an inverse association between neighborhood greenspace and depression has been observed in several studies [46-48], suggesting that greenspace may improve neurological health. Greenspace also provides a setting for social interaction $[49,50]$ and engagement with nature, both of which have been associated with mood [51,52] and are beneficial particularly for the elderly [53].

Similarly, we observed a negative association between water and AD rate. The beneficial effects of proximity to blue space may also be related to the promotion of physical activities and social interaction, and stress reduction [22,24,53]. Relative to PM2.5, water does not filter air pollutants directly; however, surrounding wetlands may decrease concentrations of air pollutants, including particulate matter [54]. In addition, pollutants and particulates are more likely to be suspended in the air when it is very dry; near water areas with higher humidity, air pollutants may be reduced [55].

Our results also revealed that the risk of AD was negatively associated with household median income and population density. It is possible that the causal mechanisms involved in AD differ in urban versus rural occupations, and that air filtration, physical activity, and other benefits of greenspace vary across urban and rural landscapes and vegetation types.

One major strength of this epidemiological analysis is that we used high-resolution classified land cover to measure greenspace. Many previous studies used the normalized difference vegetation index (NDVI) to quantify average "greenness" or used mediumresolution remotely sensed images to calculate greenspace. The 1-m land cover data provide more accurate measures of greenspace than those in other studies. Second, our study was conducted across a large spatial extent. Since factors associated with AD are expected to be subtle, the larger spatial extent of the data may allow better discrimination of potential associations, thus potentially increasing the significance of the association between greenspace and the risk of AD.

Our study has a few limitations. First, we do not have any information about where, when, or how long residents were exposed to greenspace. Therefore, the exposure is unclear and is represented only by the percentage of greenspace in the residential Zip code. Second, because of the scarcity of high-resolution imagery, we investigated only three-year data, which is a relatively short period for studying AD. Furthermore, our study was observational rather than experimental, and it was conducted at the ZIP code level instead of the individual level due to the shortage of finer spatial resolution of the Medicare 
data. The associations at the ZIP code level are more likely subject to confounding bias if the background rate of the disease is correlated with those confounding factors. This study design cannot confirm a causal relationship between greenspace or blue space and $\mathrm{AD}$ rate. Although this ecological study has many limitations due to data availability and the difficulty of the question, this work is the first to explore potential health benefits of green space on $\mathrm{AD}$. Given the high rate of $\mathrm{AD}$, exposure to greenspace and blue space may be a feasible way to delay or mitigate the development of $\mathrm{AD}$, thus reducing the cost of $\mathrm{AD}$ health care and the suffering of $\mathrm{AD}$ patients and their families.

\section{Conclusions}

We observed a lower $\mathrm{AD}$ rate associated with increasing greenspace and water area in the mid-Atlantic US. This relationship remained when our model was adjusted for PM2.5, income, and population density, and it was consistent across seasons, gender, and race. The possible benefits of greenspace and blue space may occur through multiple pathways, but as of yet, these are unclear and require further investigation.

Author Contributions: Conceptualization, J.W. and L.J.; methodology, J.W. and L.J.; Data analysis, J.W.; writing, J.W. and L.J.; funding acquisition, L.J. All authors have read and agreed to the published version of the manuscript.

Funding: This research was supported by an appointment to the Research Participation Program at the US EPA, Office of Research and Development (ORD), administered by the Oak Ridge Institute for Science and Education (ORISE) through interagency agreement DW-89-92429801 between the US Department of Energy and EPA. Funding was provided by ORD through its Sustainable and Healthy Communities Research Program.

Data Availability Statement: The data will be deposited in ScienceHub at EPA except the Alzheimer's disease data, which are held by the Center for Medicaid and Medicare (CMS).

Acknowledgments: The research described in this article has been reviewed by the Center for Public Health and Environmental Assessment, US EPA, and approved for publication. Approval does not signify that the contents necessarily reflect the views and policies of the Agency, nor does the mention of trade names of commercial products constitute endorsement or recommendation for use.

Conflicts of Interest: The authors declare no conflict of interest.

\section{References}

1. Reitz, C.; Mayeux, R. Alzheimer disease: Epidemiology, diagnostic criteria, risk factors and biomarkers. Biochem. Pharmacol. 2014, 88, 640-651. [CrossRef] [PubMed]

2. Bloom, G.S. Amyloid- $\beta$ and tau: The trigger and bullet in Alzheimer disease pathogenesis. JAMA Neurol. 2014, 71, 505-508. [CrossRef]

3. Ittner, L.M.; Götz, J. Amyloid- $\beta$ and tau—a toxic pas de deux in Alzheimer's disease. Nat. Rev. Neurosci. 2011, 12, 67. [CrossRef] [PubMed]

4. Alzheimer's Association. Alzheimer's disease facts and figures. Alzheimer's Dement. 2016, 12, 459-509.

5. Hebert, L.E.; Weuve, J.; Scherr, P.A.; Evans, D.A. Alzheimer disease in the United States (2010-2050) estimated using the 2010 census. Neurology 2013, 80, 1778-1783. [CrossRef] [PubMed]

6. Mangialasche, F.; Solomon, A.; Winblad, B.; Mecocci, P.; Kivipelto, M. Alzheimer's disease: Clinical trials and drug development. Lancet Neurol. 2010, 9, 702-716. [CrossRef]

7. Reitz, C.; Brayne, C.; Mayeux, R. Epidemiology of Alzheimer disease. Nat. Rev. Neurol. 2011, 7, 137-152. [CrossRef]

8. Mayeux, R.; Stern, Y. Epidemiology of Alzheimer disease. Cold Spring Harb. Perspect. Med. 2012, 2, a006239. [CrossRef] [PubMed]

9. Tanzi, R.E. The genetics of Alzheimer disease. Cold Spring Harb. Perspect. Med. 2012, 2, a006296. [CrossRef]

10. Chin-Chan, M.; Navarro-Yepes, J.; Quintanilla-Vega, B. Environmental pollutants as risk factors for neurodegenerative disorders: Alzheimer and Parkinson diseases. Front. Cell. Neurosci. 2015, 9, 124. [CrossRef]

11. Liu, C.-C.; Kanekiyo, T.; Xu, H.; Bu, G. Apolipoprotein E and Alzheimer disease: Risk, mechanisms and therapy. Nat. Rev. Neurol. 2013, 9, 106. [CrossRef]

12. Yankner, B.A. Mechanisms of neuronal degeneration in Alzheimer's disease. Neuron 1996, 16, 921-932. [CrossRef]

13. Moulton, P.V.; Yang, W. Air pollution, oxidative stress, and Alzheimer's disease. J. Environ. Public Health 2012, 2012. [CrossRef]

14. Yegambaram, M.; Manivannan, B.; Beach, T.G.; Halden, R.U. Role of environmental contaminants in the etiology of Alzheimer's disease: A review. Curr. Alzheimer Res. 2015, 12, 116-146. [CrossRef] 
15. Jung, C.-R.; Lin, Y.-T.; Hwang, B.-F. Ozone, particulate matter, and newly diagnosed Alzheimer's disease: A population-based cohort study in Taiwan. J. Alzheimer's Dis. 2015, 44, 573-584. [CrossRef] [PubMed]

16. Kioumourtzoglou, M.-A.; Schwartz, J.D.; Weisskopf, M.G.; Melly, S.J.; Wang, Y.; Dominici, F.; Zanobetti, A. Long-term PM2. 5 exposure and neurological hospital admissions in the northeastern United States. Environ. Health Perspect. 2015, 124, 23-29. [CrossRef] [PubMed]

17. Oudin, A.; Forsberg, B.; Adolfsson, A.N.; Lind, N.; Modig, L.; Nordin, M.; Nordin, S.; Adolfsson, R.; Nilsson, L.-G. Traffic-related air pollution and dementia incidence in Northern Sweden: A longitudinal study. Environ. Health Perspect. 2015, 124, 306-312. [CrossRef] [PubMed]

18. Lee, A.C.; Maheswaran, R. The health benefits of urban green spaces: A review of the evidence. J. Public Health 2011, 33, $212-222$. [CrossRef]

19. Markevych, I.; Schoierer, J.; Hartig, T.; Chudnovsky, A.; Hystad, P.; Dzhambov, A.M.; De Vries, S.; Triguero-Mas, M.; Brauer, M.; Nieuwenhuijsen, M.J. Exploring pathways linking greenspace to health: Theoretical and methodological guidance. Environ. Res. 2017, 158, 301-317. [CrossRef]

20. Van den Berg, M.; van Poppel, M.; van Kamp, I.; Andrusaityte, S.; Balseviciene, B.; Cirach, M.; Danileviciute, A.; Ellis, N.; Hurst, G.; Masterson, D. Visiting green space is associated with mental health and vitality: A cross-sectional study in four european cities. Health Place 2016, 38, 8-15. [CrossRef] [PubMed]

21. $\mathrm{Wu}, \mathrm{J} . ;$ Jackson, L. Inverse relationship between urban green space and childhood autism in California elementary school districts. Environ. Int. 2017, 107, 140-146. [CrossRef] [PubMed]

22. Völker, S.; Kistemann, T. The impact of blue space on human health and well-being-Salutogenetic health effects of inland surface waters: A review. Int. J. Hyg. Environ. Health 2011, 214, 449-460. [CrossRef]

23. Völker, S.; Kistemann, T. Reprint of:"I'm always entirely happy when I'm here!” Urban blue enhancing human health and well-being in Cologne and Düsseldorf, Germany. Soc. Sci. Med. 2013, 91, 141-152. [CrossRef] [PubMed]

24. Gascon, M.; Triguero-Mas, M.; Martínez, D.; Dadvand, P.; Forns, J.; Plasència, A.; Nieuwenhuijsen, M.J. Mental health benefits of long-term exposure to residential green and blue spaces: A systematic review. Int. J. Environ. Res. Public Health 2015, 12, 4354-4379. [CrossRef]

25. Amoly, E.; Dadvand, P.; Forns, J.; López-Vicente, M.; Basagaña, X.; Julvez, J.; Alvarez-Pedrerol, M.; Nieuwenhuijsen, M.J.; Sunyer, J. Green and blue spaces and behavioral development in Barcelona schoolchildren: The BREATHE project. Environ. Health Perspect. 2014, 122, 1351-1358. [CrossRef] [PubMed]

26. Nowak, D.J. Air Pollution Removal by Chicago's Urban Forest; Gen. Tech. Rep. NE-186; U.S. Department of Agriculture, Forest Service, Northeastern Forest Experiment Station: Radnor, PA, USA, 1994; pp. 83-94.

27. Cheapeake Bay Watershed Land Cover 2013/2014. Available online: https://chesapeakeconservancy.org/conservationinnovation-center/high-resolution-data (accessed on 27 February 2021).

28. US ZIP Code Boundary GIS Layer. Available online: https:/ /www.census.gov/programs-surveys/geography/guidance/geoareas / zctas.html (accessed on 27 February 2021).

29. US EPA. Air Quality Data. Available online: https:/ / www.epa.gov/hesc/rsig-related-downloadable-data-files (accessed on 27 February 2021).

30. Lambert, D. Zero-inflated Poisson regression, with an application to defects in manufacturing. Technometrics 1992, 34, 1-14. [CrossRef]

31. Wu, J.; Tschakert, P.; Klutse, E.; Ferring, D.; Ricciardi, V.; Hausermann, H.; Oppong, J.; Smithwick, E.A. Buruli Ulcer Disease and Its Association with Land Cover in Southwestern Ghana. PLoS Negl. Trop. Dis. 2015, 9, e0003840. [CrossRef] [PubMed]

32. Chen, L.; Liu, C.; Zhang, L.; Zou, R.; Zhang, Z. Variation in Tree Species Ability to Capture and Retain Airborne Fine Particulate Matter (PM2.5). Sci. Rep. 2017, 7, 3206. [CrossRef]

33. Nguyen, T.; Yu, X.; Zhang, Z.; Liu, M.; Liu, X. Relationship between types of urban forest and PM2.5 capture at three growth stages of leaves. J. Environ. Sci. 2015, 27, 33-41. [CrossRef] [PubMed]

34. Nowak, D.J.; Hirabayashi, S.; Bodine, A.; Greenfield, E. Tree and forest effects on air quality and human health in the United States. Environ. Pollut. 2014, 193, 119-129. [CrossRef]

35. Gopalakrishnan, V.; Hirabayashi, S.; Ziv, G.; Bakshi, B.R. Air quality and human health impacts of grasslands and shrublands in the United States. Atmos. Environ. 2018, 182, 193-199. [CrossRef]

36. Stephen, R.; Hongisto, K.; Solomon, A.; Lönnroos, E. Physical activity and Alzheimer's disease: A systematic review. J. Gerontol. Ser. A Biomed. Sci. Med. Sci. 2017, 72, 733-739. [CrossRef]

37. Blondell, S.J.; Hammersley-Mather, R.; Veerman, J.L. Does physical activity prevent cognitive decline and dementia?: A systematic review and meta-analysis of longitudinal studies. BMC Public Health 2014, 14, 510. [CrossRef] [PubMed]

38. Coutts, C. Greenway accessibility and physical-activity behavior. Environ. Plan. B Plan. Des. 2008, 35, 552-563. [CrossRef]

39. Shafer, C.S.; Scott, D.; Mixon, J. A Greenway Classification System: Defining the Function and Character of Greenways in Urban Areas. J. Park Recreat. Adm. 2000, 18, 88-106.

40. Wu, J.; Rappazzo, K.M.; Simpson Jr, R.J.; Joodi, G.; Pursell, I.W.; Mounsey, J.P.; Cascio, W.E.; Jackson, L.E. Exploring links between greenspace and sudden unexpected death: A spatial analysis. Environ. Int. 2018, 113, 114-121. [CrossRef]

41. Barnes, D.E.; Yaffe, K. The projected effect of risk factor reduction on Alzheimer's disease prevalence. Lancet Neurol. 2011, 10, 819-828. [CrossRef] 
42. Rovner, B.W.; Broadhead, J.; Spencer, M.; Carson, K.; Folstein, M.F. The American Journal of Psychiatry. Am. J. Psychiatry 1989, $146,350-353$.

43. Diniz, B.S.; Butters, M.A.; Albert, S.M.; Dew, M.A.; Reynolds, C.F. Late-life depression and risk of vascular dementia and Alzheimer's disease: Systematic review and meta-analysis of community-based cohort studies. Br. J. Psychiatry 2013, 202, 329-335. [CrossRef]

44. Mazumdar, S.; Dunshea, A.; Chong, S.; Jalaludin, B. Tree Canopy Cover Is Best Associated with Perceptions of Greenspace: A Short Communication. Int. J. Environ. Res. Public Health 2020, 17, 6501. [CrossRef]

45. Astell-Burt, T.; Navakatikyan, M.A.; Feng, X. Urban green space, tree canopy and 11-year risk of dementia in a cohort of 109,688 Australians. Environ. Int. 2020, 145, 106102. [CrossRef]

46. Miles, R.; Coutts, C.; Mohamadi, A. Neighborhood urban form, social environment, and depression. J. Urban Health 2012, 89, 1-18. [CrossRef]

47. Roe, J.; Thompson, C.; Aspinall, P.; Brewer, M.; Duff, E.; Miller, D.; Mitchell, R.; Clow, A. Green space and stress: Evidence from cortisol measures in deprived urban communities. Int. J. Environ. Res. Public Health 2013, 10, 4086-4103. [CrossRef]

48. Thompson, C.W.; Roe, J.; Aspinall, P.; Mitchell, R.; Clow, A.; Miller, D. More green space is linked to less stress in deprived communities: Evidence from salivary cortisol patterns. Landsc. Urban Plan. 2012, 105, 221-229. [CrossRef]

49. Holtan, M.T.; Dieterlen, S.L.; Sullivan, W.C. Social life under cover: Tree canopy and social capital in Baltimore, Maryland. Environ. Behav. 2015, 47, 502-525. [CrossRef]

50. Kweon, B.-S.; Sullivan, W.C.; Wiley, A.R. Green common spaces and the social integration of inner-city older adults. Environ. Behav. 1998, 30, 832-858. [CrossRef]

51. Carrus, G.; Scopelliti, M.; Lafortezza, R.; Colangelo, G.; Ferrini, F.; Salbitano, F.; Agrimi, M.; Portoghesi, L.; Semenzato, P.; Sanesi, G. Go greener, feel better? The positive effects of biodiversity on the well-being of individuals visiting urban and peri-urban green areas. Landsc. Urban Plan. 2015, 134, 221-228. [CrossRef]

52. Maas, J.; Van Dillen, S.M.; Verheij, R.A.; Groenewegen, P.P. Social contacts as a possible mechanism behind the relation between green space and health. Health Place 2009, 15, 586-595. [CrossRef] [PubMed]

53. Finlay, J.; Franke, T.; McKay, H.; Sims-Gould, J. Therapeutic landscapes and wellbeing in later life: Impacts of blue and green spaces for older adults. Health Place 2015, 34, 97-106. [CrossRef] [PubMed]

54. Zhu, C.; Zeng, Y. Effects of urban lake wetlands on the spatial and temporal distribution of air PM10 and PM2. 5 in the spring in Wuhan. Urban For. Urban Green. 2018, 31, 142-156. [CrossRef]

55. Kupryś-Lipińska, I.; Kuna, P.; Wagner, I. Water in the urban space and the health of residents. Water City Sendzimir Found. Kraków 2014, 88, 47-55. 